\title{
Infective endocarditis: Updated guidelines
}

U Allen; Canadian Paediatric Society, Infectious Diseases and Immunization Committee

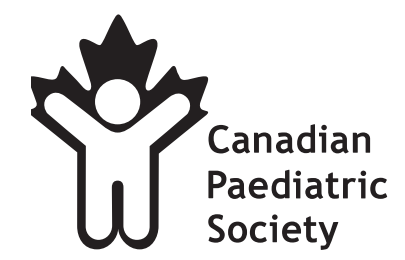

U Allen; Canadian Paediatric Society, Infectious Diseases and Immunization Committee. Infective endocarditis: Updated guidelines. Can J Infect Dis Med Microbiol 2010;21(2):74-77.

The most recent revision of the American Heart Association guidelines on infective endocarditis prophylaxis occurred in 2007. These revisions were based on the fact that current data have brought into question the benefit of previous recommendations for infective endocarditis prophylaxis. It was noted that the bacteremia that occurs following dental procedures represents only a fraction of the episodes of bacteremia that occur with activities of daily living (such as chewing, brushing teeth and other oral hygiene measures). The target groups and the procedures for which prophylaxis is reasonable have been significantly reduced in number. The focus is now on patients who are most likely to have adverse outcomes from infectious endocarditis. The present article is targeted at practicing Canadian physicians and provides the rationale for the current recommendations. In addition to a summary of the indications for prophylaxis, information is provided on the conditions for which prophylaxis is not recommended.

Key Words: Bacteremia; Congenital heart disease; Infective endocarditis; Prophylaxis

Tn 2007, the American Heart Association (AHA) and the British Society for Antimicrobial Chemotherapy undertook major revisions of their infective endocarditis (IE) prophylaxis guidelines. These revisions were aimed at simplifying recommendations and ensuring consistency with the published evidence over the past two decades $(1,2)$. The target groups and the procedures for which prophylaxis is reasonable have been drastically reduced in number. The current article is a synopsis of the AHA Committee's recommendations, along with a provision of the rationale for the recommendations. The full guidelines are available at http://circ.ahajournals.org and were endorsed by the Infectious Diseases Society of America, the Pediatric Infectious Diseases Society and the Council on Scientific Affairs of the American Dental Association.

\section{PRIMARY REASONS FOR REVISION OF THE AHA GUIDELINES}

The new guidelines were not based on the results of a single study but rather on the collective body of evidence published in numerous studies over the past two decades. The Committee sought to construct the present guidelines such

\section{L'endocardite infectieuse : Mise à jour des lignes directrices}

La plus récente révision des lignes directrices de l'American Heart Association sur la prophylaxie de l'endocardite infectieuse a été effectuée en 2007, parce que les données à jour remettaient en question les bienfaits des recommandations précédentes sur la prophylaxie de l'endocardite infectieuse. On y soulignait que la bactériémie suscitée par des interventions dentaires ne représente qu'une fraction des épisodes de bactériémie suscités par les activités de la vie quotidienne (comme la mastication, le brossage des dents et d'autres mesures d'hygiène buccale). Le nombre de groupes cibles et d'interventions qui justifient une prophylaxie a considérablement diminué. On s'attarde maintenant aux patients les plus susceptibles de subir une réaction indésirable causée par une endocardite infectieuse. Le présent article s'adresse aux médecins canadiens en exercice et expose la raison d'être des recommandations à jour. En plus de contenir un résumé des indications de prophylaxie, il renferme de l'information sur les maladies pour lesquelles la prophylaxie n'est pas recommandée.

that they would be in the best interest of patients and providers, would be reasonable and prudent, and would represent the conclusions of published studies and the collective wisdom of many experts on IE and relevant national and international societies. Four primary reasons were cited to form the rationale for revising the guidelines:

- IE is much more likely to result from frequent exposure to random bacteremias associated with daily activities than from bacteremia caused by a dental, gastrointestinal (GI) tract or genitourinary (GU) tract procedure.

- Prophylaxis prevents an exceedingly small number of cases of IE, if any, in individuals who undergo a dental, GI tract or GU tract procedure.

- The risk of antibiotic-associated adverse events exceeds the benefit, if any, from prophylactic antibiotic therapy except in very high-risk situations.

- Maintenance of optimal oral health and hygiene may reduce the incidence of bacteremia from daily activities and thus the risk of IE, and is more important than the use of prophylactic antibiotics for dental procedures. 


\section{TARGET GROUPS FOR PROPHYLAXIS}

The new guidelines suggest that prophylaxis should be targeted at conditions that are associated with the highest probability of adverse outcomes from IE. For example, it has been determined that the risk of mortality from IE due to viridans streptococcal infection of prosthetic valves is at least 20\% (3-5), while the mortality in the case of native valves is $5 \%$ or less $(6-8)$. In this regard, prophylaxis is reasonable for patients with the following conditions (Table 1):

- Prosthetic cardiac valve or prosthetic material used for valve repair

- Previous IE

- Congenital heart disease (CHD)

- Unrepaired cyanotic CHD, including palliative shunts and conduits

- Completely repaired congenital heart defect with prosthetic material or device, whether placed by surgery or by catheter intervention, during the first six months after the procedure

- Repaired CHD with residual defects at the site or adjacent to the site of a prosthetic patch or prosthetic device (which inhibit endothelialization)

- Cardiac transplant recipients who develop cardiac valvulopathy

It should be noted that with the exception of the conditions listed above, antibiotic prophylaxis is no longer recommended for any other form of CHD. With respect to prosthetic material, prophylaxis is reasonable for six months because endothelialization of prosthetic material usually occurs within six months after valve placement.

In the new guidelines, the Committee noted that mitral valve prolapse (MVP) is the most common underlying condition that predisposes to the acquisition of IE in the western world, but the absolute incidence of IE is extremely low in this population. In addition, IE with MVP is not usually associated with the grave outcomes associated with the conditions noted above. Consequently, IE prophylaxis is no longer recommended for patients with MVP.

The new guidelines did not specifically address the issue of rheumatic heart disease. However, in some centres, patients with significant residual valvular disease due to rheumatic heart disease continue to be regarded as candidates for prophylaxis (9). This notwithstanding, current AHA recommendations no longer routinely suggest prophylaxis for patients with rheumatic heart disease (10).

DENTAL PROCEDURES FOR WHICH ENDOCARDITIS PROPHYLAXIS IS REASONABLE FOR PATIENTS IN THE HIGH-RISK TARGET GROUP

In addition to identifying the underlying cardiac conditions that warrant prophylaxis, the Committee addressed the dental procedures for which prophylaxis is warranted if such procedures are performed in high-risk patients.
TABLE 1

Indications for prophylaxis against infective endocarditis in patients undergoing dental procedures

\begin{tabular}{ll}
\hline Prophylaxis indicated & Prophylaxis not indicated \\
\hline Prosthetic cardiac valves & Atrial septic defects \\
Previous infective endocarditis & Ventricular septal defects \\
Unrepaired cyanotic congenital heart & Patent ductus arteriosus \\
disease, including palliative shunts & Mitral valve prolapse \\
and conduits & Previous Kawasaki disease \\
Completely repaired congenital heart & Hypertrophic cardiomyopathy \\
defect with prosthetic material or & Previous coronary artery bypass \\
device, during the first six months & graft surgery \\
after the procedure & Cardiac pacemakers (intravascular \\
Repaired congenital heart disease & and epicardial) and implanted \\
with residual defects at the site or & defibrillators \\
adjacent to the site of a prosthetic & Bicuspid aortic valves \\
patch or prosthetic device (which & Coarctation of the aorta \\
inhibit endothelialization) & Calcified aortic stenosis \\
Cardiac transplant recipients with & Pulmonic stenosis \\
cardiac valvulopathy & \\
Rheumatic heart disease if prosthetic & \\
valves or prosthetic material used in & \\
valve repair & \\
\hline
\end{tabular}

The duration of bacteremia following several activities of daily living, such as chewing food and tooth brushing, far exceed that due to a single tooth extraction, for example $(11,12)$. For illustrative purposes, these durations have been estimated to be 5730 min over a one-month period for the activities of daily living (11), compared with $6 \mathrm{~min}$ to $30 \mathrm{~min}$ for a single tooth extraction (12). The procedures for which prophylaxis is reasonable are as follows:

- All dental procedures that involve the manipulation of gingival tissue, the periapical region of teeth or the perforation of the oral mucosa.

The following procedures and events do not require prophylaxis:

- Routine anesthetic injections through noninfected tissue, taking dental radiographs, placement of removable prosthodontic or orthodontic appliances, adjustment of orthodontic appliances, placement of orthodontic brackets, shedding of deciduous teeth, and bleeding from trauma to the lips or oral mucosa.

\section{ANTIBIOTIC REGIMENS FOR DENTAL AND OTHER PROCEDURES}

Antibiotics for prophylaxis should be administered in a single dose before the procedure. If the antibiotic is inadvertently not given before the procedure, it may be administered up to $2 \mathrm{~h}$ after the procedure. It should be noted that rarely, some patients who are scheduled for an invasive procedure may have a coincidental IE. The presence of fever or other manifestations of systemic infection should alert the provider to the possibility of IE, and it is important to obtain blood cultures and other relevant tests before administration of antibiotics intended to prevent IE. This is important in preventing a delay in the diagnosis or treatment of a concomitant case of IE. 
TABLE 2

Antibiotic regimens for dental procedures (single dose administered $30 \mathrm{~min}$ to $60 \mathrm{~min}$ before the procedure)

\begin{tabular}{|c|c|c|c|}
\hline Situation & Agent & Adults & Children \\
\hline Able to take oral medication & Amoxicillin & $2 \mathrm{~g}$ & $50 \mathrm{mg} / \mathrm{kg}$ \\
\hline \multirow[t]{2}{*}{ Unable to take oral medication } & Ampicillin & $2 \mathrm{~g} \mathrm{IM}$ or IV & $50 \mathrm{mg} / \mathrm{kg}$ IM or IV \\
\hline & Cefazolin or ceftriaxone & $1 \mathrm{~g} \mathrm{IM}$ or IV & $50 \mathrm{mg} / \mathrm{kg}$ IM or IV \\
\hline \multirow[t]{3}{*}{ Allergic to penicillin or ampicillin } & Cephalexin & $2 \mathrm{~g}$ & $50 \mathrm{mg} / \mathrm{kg}$ \\
\hline & Clindamycin & $600 \mathrm{mg}$ & $20 \mathrm{mg} / \mathrm{kg}$ \\
\hline & Azithromycin or clarithromycin & $500 \mathrm{mg}$ & $15 \mathrm{mg} / \mathrm{kg}$ \\
\hline \multirow{2}{*}{$\begin{array}{l}\text { Allergic to penicillin or ampicillin and } \\
\text { unable to take oral medication }\end{array}$} & Cefazolin or ceftriaxone & $1 \mathrm{~g} \mathrm{IM}$ or IV & $50 \mathrm{mg} / \mathrm{kg}$ IM or IV \\
\hline & Clindamycin & $600 \mathrm{mg}$ IM or IV & $20 \mathrm{mg} / \mathrm{kg}$ IM or IV \\
\hline
\end{tabular}

IM Intramuscular; IV Intravenous

\section{Dental procedures}

Table 2 summarizes the recommended antibiotic regimens for dental procedures. Amoxicillin is the preferred choice for oral therapy because it is well absorbed from the GI tract and provides high and sustained serum concentrations. For individuals who are allergic to penicillin or amoxicillin, the use of cephalexin or another first-generation oral cephalosporin, clindamycin, azithromycin or clarithromycin is recommended. Cephalosporins should not be administered to patients with a history of penicillin hypersensitivity reactions that resulted in systemic anaphylaxis, angioedema or urticaria. Patients who are unable to tolerate an oral antibiotic may be treated with parenteral ampicillin, ceftriaxone or cefazolin. Ampicillin-allergic patients who are unable to tolerate an oral agent may be treated with parenteral cefazolin, ceftriaxone or clindamycin (avoiding the cephalosporins if there is a history of anaphylaxis, angioedema or urticaria).

\section{Respiratory tract procedures}

Patients who require prophylaxis may be given the regimens in Table 2. This applies to individuals who undergo an invasive procedure of the respiratory tract that involves incision or biopsy of the respiratory mucosa, such as tonsillectomy and adenoidectomy. Prophylaxis is not required for bronchoscopy unless the procedure involves incision of the respiratory tract mucosa. If a patient is undergoing a procedure for an established respiratory tract infection, the regimen should include antibiotics that are effective against the likely pathogens in addition to viridans streptococci. For example, antistaphylococcal agents should be used if infection is known or suspected to be caused by Staphylococcus aureus.

\section{GI or GU tract procedures}

Prophylaxis is no longer recommended for these patients. However, for high-risk patients who have an established GI or GU tract infection, or for those who receive antibiotic therapy to prevent wound infection or sepsis associated with a GI or GU tract procedure, the antibiotic regimen should include an agent active against enterococci, such as ampicillin or vancomycin.

For high-risk patients who are scheduled for an elective cystoscopy or other urinary tract manipulation and who have an enterococcal urinary tract infection or colonization, antibiotic therapy to eradicate enterococci from the urine before the procedure may be considered. If the urinary tract procedure is not elective, it may be reasonable to include an agent active against enterococci in the empiric or specific perioperative antimicrobial regimen administered to the patient.

\section{Procedures on infected skin, skin structure or musculoskeletal tissue}

The antibiotic regimen should include coverage against staphylococci and group A streptococci. Appropriate agents include an antistaphylococcal penicillin or cephalosporin. Vancomycin or clindamycin may be used in patients allergic to beta-lactams. If methicillin-resistant $S$ aureus is suspected, vancomycin is recommended.

\section{SUMMARY}

The 2007 AHA guidelines are significantly different from previous guidelines, with significantly fewer patients being targeted for prophylaxis. Clinicians should become familiar with these guidelines - a synopsis of the guidelines is provided in the present document. The AHA Committee recognizes the need for more data to guide future changes to the IE prophylaxis guidelines. Prospectively designed clinical studies are encouraged. Given the low incidence of IE, such studies would need to be multicentred and would take several years to complete.

\section{REFERENCES}

1. Wilson W, Taubert KA, Gewitz M, et al. Prevention of infective endocarditis: A guideline from the American Heart Association Rheumatic Fever, Endocarditis, and Kawasaki Disease Committee, Council on Cardiovascular Disease in the Young, and the Council on Clinical Cardiology, Council on Cardiovascular Surgery and Anesthesia, and the Quality of Care and Outcomes Research Interdisciplinary Working Group. Circulation 2007;116:1736-54.

2. Gould FK, Elliott TS, Foweraker J, et al. Guidelines for the prevention of endocarditis: Report of the Working Party of the British Society for Antimicrobial Chemotherapy. J Antimicrob Chemother 2006;57:1035-42.

3. Wilson WR, Jaumin PM, Danielson GK, Giuliani ER, Washington JA II, Geraci JE. Prosthetic valve endocarditis. Ann Intern Med 1975;82:751-6.

4. Baddour LM, Wilson WR. Infections of prosthetic valves and other cardiovascular devices. In: Mandell GL, Bennett JE, Dolin R, eds. Principles and Practice of Infectious Diseases. Philadelphia: Elsevier Churchill Livingstone, 2005:1022-44.

5. Wilson WR, Danielson GK, Giuliani ER, Geraci JE. Prosthetic valve endocarditis. Mayo Clin Proc 1982;57:155-61. 
6. Wilson WR, Geraci JE, Wilkowske CJ, Washington JA II. Shortterm intramuscular therapy with procaine penicillin plus streptomycin for infective endocarditis due to viridans streptococci. Circulation 1978;57:1158-61.

7. Sexton DJ, Tenenbaum MJ, Wilson WR, et al. Ceftriaxone once daily for four weeks compared with ceftriaxone plus gentamicin once daily for two weeks for treatment of endocarditis due to penicillin-susceptible streptococci. Endocarditis Treatment Consortium Group. Clin Infect Dis 1998;27:1470-4.

8. Francioli P, Etienne J, Hoigne R, Thys JP, Gerber A. Treatment of streptococcal endocarditis with a single daily dose of ceftriaxone sodium for 4 weeks: Efficacy and outpatient treatment feasibility. JAMA 1992;267:264-7.

9. Drug Handbook and Formulary 2009-2010. Hospital for Sick Children. Toronto: Drug Information Service, 2009.
10. Gerber MA, Baltimore RS, Eaton CB, et al. Prevention of rheumatic fever and diagnosis and treatment of acute Streptococcal pharyngitis: A scientific statement from the American Heart Association Rheumatic Fever, Endocarditis, and Kawasaki Disease Committee of the Council on Cardiovascular Disease in the Young, the Interdisciplinary Council on Functional Genomics and Translational Biology, and the Interdisciplinary Council on Quality of Care and Outcomes Research: Endorsed by the American Academy of Pediatrics. Circulation 2009;119:1541-51.

11. Guntheroth WG. How important are dental procedures as a cause of infective endocarditis? Am J Cardiol 1984;54:797-801.

12. Roberts GJ. Dentists are innocent! "Everyday" bacteremia is the real culprit: A review and assessment of the evidence that dental surgical procedures are a principal cause of bacterial endocarditis in children. Pediatr Cardiol 1999;20:317-25.

\section{INFECTIOUS DISEASES AND IMMUNIZATION COMMITTEE}

Members: Drs Robert Bortolussi, IWK Health Centre, Halifax, Nova Scotia (Chair); Jane Finlay, Richmond, British Columbia; Jane C McDonald, The Montreal Children's Hospital, Montreal, Quebec; Heather Onyett, Kingston General Hospital, Kingston, Ontario; Joan L Robinson, Edmonton, Alberta; Élisabeth Rousseau-Harsany, Sainte-Justine UHC, Montreal, Quebec (Board Representative)

Liaisons: Drs Upton D Allen, The Hospital for Sick Children, Toronto, Ontario (Canadian Pediatric AIDS Research Group); Charles PS Hui, Children's Hospital of Eastern Ontario, Ottawa, Ontario (CPS Liaison to Health Canada, Committee to Advise on Tropical Medicine and Travel); Nicole Le Saux, Children's Hospital of Eastern Ontario, Ottawa, Ontario (Immunization Program, ACTive); Larry Pickering, Elk Grove, Illinois, USA (American Academy of Pediatrics); Marina I Salvadori, Children's Hospital of Western Ontario, Ottawa, Ontario (CPS Liaison to Health Canada, National Advisory Committee on Immunization)

Consultants: Drs James Kellner, Calgary, Alberta; Noni E MacDonald, IWK Health Centre, Halifax, Nova Scotia; Dorothy L Moore, The Montreal Children's Hospital, Montreal, Quebec

Principal author: Dr Upton D Allen, Toronto, Ontario

All Canadian Paediatric Society position statements/notes are reviewed, revised or retired as needed on a regular basis. For the current version, please consult the "Position Statements" section of the CPS website (www.cps.ca/english/publications/statementsindex.htm). This article also appears in the April 2010 issue of Paediatrics $\mathbb{E}$ Child Health. 


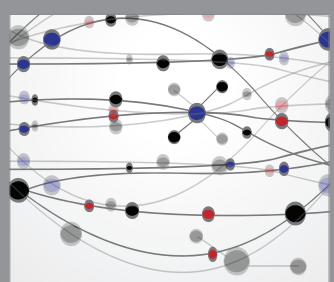

The Scientific World Journal
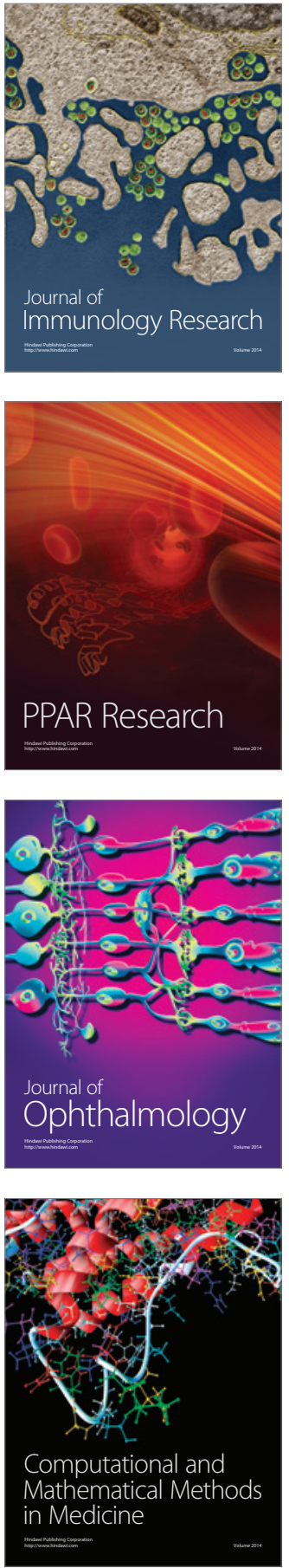

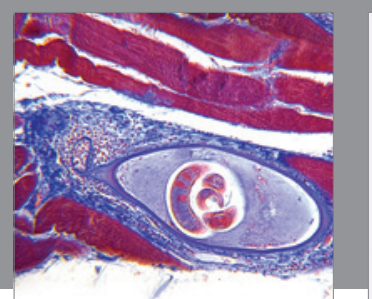

Gastroenterology Research and Practice

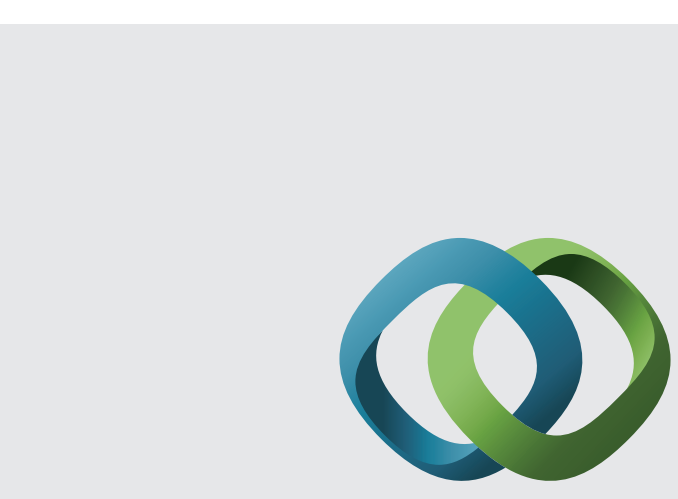

\section{Hindawi}

Submit your manuscripts at

http://www.hindawi.com
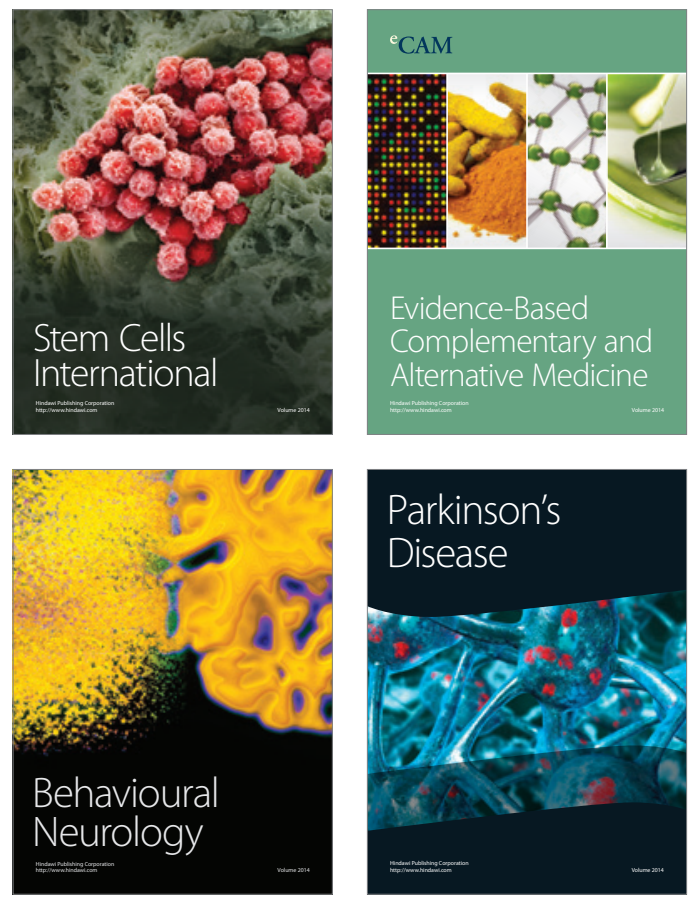
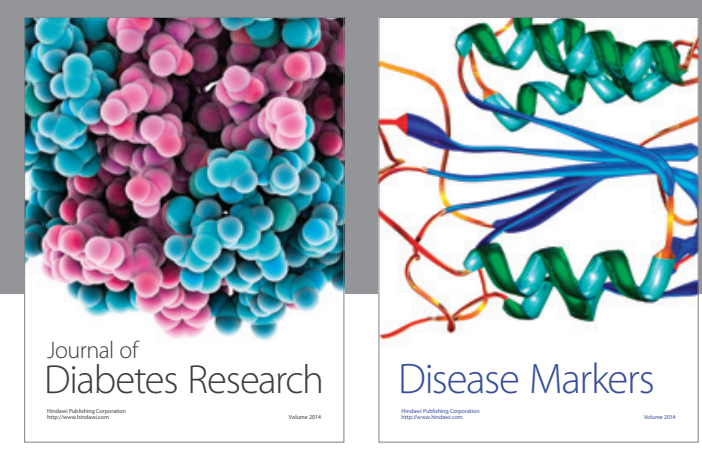

Disease Markers
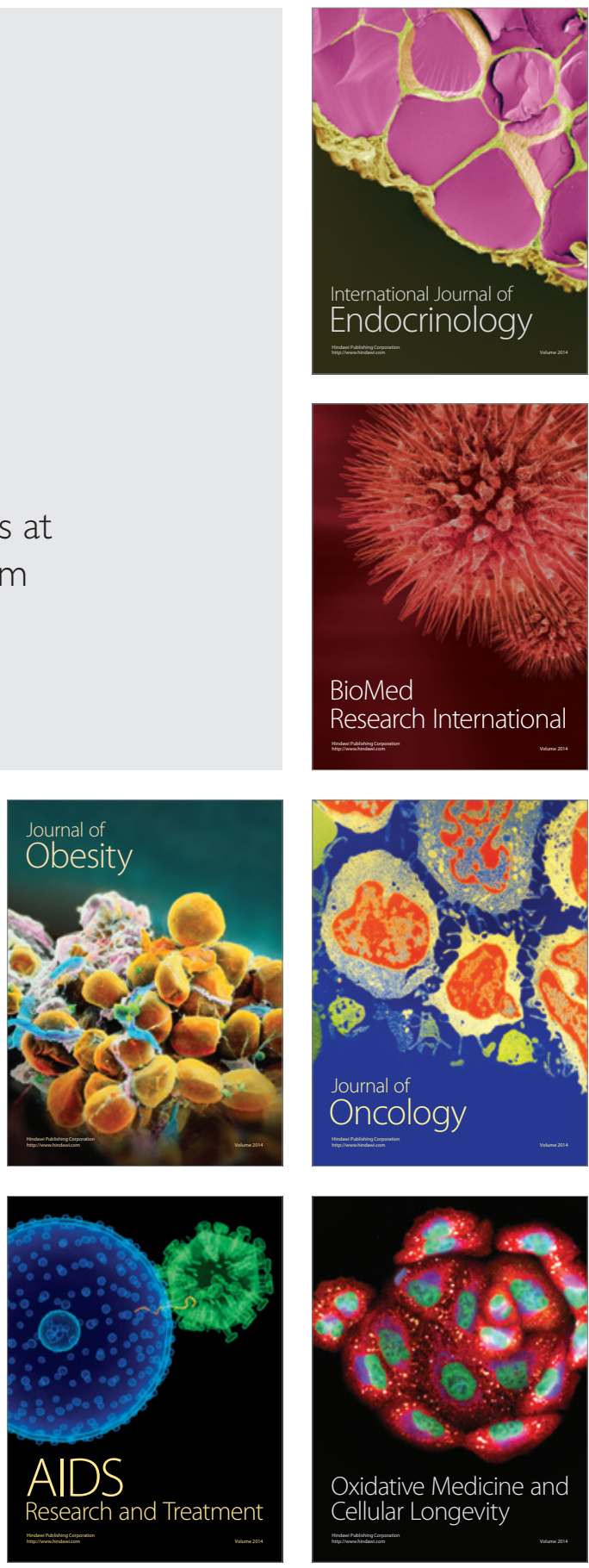